\title{
Correlational Analysis Between Depression and Health Behavior Among Employees in the State of Louisiana
}

\author{
Sharon Njie \\ Department of Public Policy, Southern University and A \& M College
}

\begin{abstract}
Depression has become a canker that is eating up the social fabric of the majority of the employees in the State of Louisiana. Depression is a complex condition that requires intervention since it can affect anyone. There are side effects of depression, such as mental, physical, and social behavior, but this study looks at the psychological side effects in the form of mental health. The research is quantitative by nature and utilizes data from County Health Rankings and Roadmaps for the State of Louisiana. Sixty-four counties were used, for a period of 3 years; that is from 2016 to 2018. Correlation analysis and linear regression model were used to analyze the health behaviors of depressed employees. The two variables considered for the study include smoking and obesity. The report was done to observe if depression causes people to exhibit health behaviors such as smoking and excessive eating leading to obesity. As part of the findings, the study underscores that depressed employees' actions have a higher adverse effect on work outcome. Also, employers' attitudes are vital in effectively managing depression within the workplace. Above all, the results highlight the need for more considerable attention to an individual with a mental health problem. The study recommends that the early symptoms and notification by the management of an employee who is undergoing a level of unhealthy behavior should be advised to seek medical assistance or possibly be enrolled by the administration for support.
\end{abstract}

Keywords: Depression, Mentally Unhealthy, Health Behaviors, Employees, Workplace

DOI: 10.7176/PPAR/9-8-06

Publication date: August $31^{\text {st }} 2019$

\subsection{INTRODUCTION}

Depression is a severe medical illness with mood, cognitive, and physical symptoms. It's associated with higher rates of chronic disease, increased health care utilization, and impaired functioning. Rates of treatment remain low, and the treatment received is often inadequate" (Pratt and Brody, 2014). Depression is rampant among employees and associated with functional disability and work damage. To date, little is known about the incidence and possible risk factors for developing anxiety and depression in the working population.

According to Martin (2010), depression is the most widespread psychiatric condition and is predicted to become the second most momentous cause of global disease burden by 2020 , estimated to affect between $20 \%$ and $55 \%$ of adults in their lifetime (Mc- Clanahan \& Antonuccio, 2004). In addition to the personal impact of depression on individuals and their social networks, significant implications for managing employment relationships and occupational health are evident globally. In the United States, $1.8 \%$ to $3.6 \%$ of workers suffer from significant depression and $17 \%$ to $21 \%$ experience short-term disability due to a depressive illness during any given year (Goldberg \& Steury, 2001). A Japanese study showed that approximately $40 \%$ of workers in Japanese companies reported suffering mild depression, $13 \%$ from moderate to severe depression, and about $10 \%$ felt suicidal (Gross \& Tran, 2003).

Also, in a study conducted by Sullivan (2005) estimated that about one-third of the economic cost of depression in society can be attributed to work disruptions and lost productivity. Research in Europe has linked depression to impaired work performance, decreased workplace safety vigilance (Haslam, Atkinson, Brown, \& Haslam, 2005), high levels of absenteeism, and early retirement (McDaid, Curran, \& Knapp, 2005). Consequently, depression has been labeled as "the occupational disability of the new millennium" (Raderstorf, 2001, p. 57), creating an increased imperative for organizations to help prevent and manage this condition (Dewa, Lesage, Goering, \& Craveen, 2004). As cited in (Philips et al., 2009) studies show that social support increases job satisfaction and commitment (Allen \& Meyer, 1990; Mathieu \& Zajac, 1990), decrease turnover and absenteeism, reduces depressive symptoms (Ganster, Fusilier, \& Mayes, 1986; Holahan, Holahan, Moos, \& Brennan, 1997), and enhances overall mental health (Anderson, 1991).

According to the National Health and Nutrition Examination Survey (2010), about 34.6\% of the United State of America adults aged 20 and over were obese, and $7.2 \%$ had depression, based on depressive symptoms experienced. The survey further revealed that both obesity and depression are associated with many health risks, including cardiovascular disease, diabetes, and functional limitations. Studies have shown higher rates of obesity in persons with depression (National Health and Nutrition Examination Survey, 2010). Perhaps, this relationship may vary by sex. Almost $11 \%$ of adults take antidepressant medication, including persons who are responding well and persons who still have moderate to severe symptoms of depression. Use of some antidepressants is positively related to obesity (Pratt and Brody, 2014). Unfortunately, despite the enormous data on depression, 
smoking behaviors, and obesity in Louisiana, little is known. Therefore, this current study theorized that depressed employees exert some health behaviors. The study utilizes correlation and regression analyses to examine the relationship between depressed employees and how they exhibit mental health behavior.

\subsection{METHODS AND MATERIALS}

The study follows a quantitative--correlational research design. In the study, data sourced from County Health Rankings and Roadmaps for the State of Louisiana. Sixty-four counties were used, spanning from a period of 3 years, that is, from 2016 to 2018 . The average number of reported cases of mentally unhealthy days per month were available for public usage. The indicators used in the study include the following: (a) Percentage of adults that reported currently smoking and, (b) the Percentage of adults that reported Body Mass Index (BMI) >=30.

Model

Multiple linear regression is the most common form of linear regression analysis. As a predictive analysis, the multiple linear regression is used to explain the relationship between one continuous dependent variable and two or more independent variables. The independent variables can be constant or categorical (dummy coded as appropriate). The dependent variable for this particular study is depression (a continuous variable), and independent variables include the percentage of smoking behaviors, and percentage of the obese population (see equation one below).

Depression $=\mathrm{B}_{0}+\mathrm{B}_{1}$ Smoking $+\mathrm{B}_{2}$ Obesity $+\mathrm{e}$

Both smoking and obesity are expected to be positively related to depression. $\mathrm{B}_{0}$ is the intercept, $\mathrm{B}_{1}$, and $\mathrm{B}_{2}$ are the values of the coefficients for smoking and obesity, respectively. The SPSS 20.0 statistical package was used for data analysis. Correlation analysis and linear regression model were used to analyze the health behaviors of depressed employees. P-values and student t-test were used to evaluate the significance of the variables. The analysis was done to observe if there is a relationship between depression and peoples' health behaviors, such as smoking and obesity.

\section{Study Hypothesis}

$\mathrm{H}_{0}$ : There is no relationship between depression and health behavior.

$\mathrm{H}_{1}$ : There is a positive relationship between depression and health behavior.

\subsection{DISCUSSION AND RESULTS}

\begin{tabular}{|c|c|c|c|c|}
\hline \multicolumn{2}{|l|}{ Correlation } & Mentally Unhealthy Days & $\%$ of Smokers & $\%$ Obese \\
\hline \multirow{3}{*}{$\begin{array}{l}\text { Mentally } \\
\text { Unhealthy Days }\end{array}$} & Pearson Correlation & 1 & $0.550^{* *}$ & $0.442^{* *}$ \\
\hline & Sig. (2-tailed) & & 0.000 & 0.000 \\
\hline & $\mathrm{N}$ & 192 & 192 & 192 \\
\hline \multirow[t]{3}{*}{ \% Smokers } & Pearson Correlation & $0.550^{* *}$ & 1 & $0.442^{* *}$ \\
\hline & Sig. (2-tailed) & 0.000 & & 0.000 \\
\hline & $\mathrm{N}$ & 192 & 192 & 192 \\
\hline \multirow[t]{3}{*}{$\%$ Obese } & Pearson Correlation & $0.442^{* *}$ & $0.442^{* *}$ & 1 \\
\hline & Sig. (2-tailed) & 0.000 & 0.000 & \\
\hline & $\mathrm{N}$ & 192 & 192 & 192 \\
\hline
\end{tabular}

In all 192 sample size were used for the data analysis. Table 1 reveals that there is a strong significant relationship between depression (or mentally unhealthy days) and percentage of smokers with a coefficient value of 0.550 at $1 \%$ and $5 \%$ significance levels. Also, the data reveal a moderately significant relationship between depression (or mentally unhealthy days) and percentage of the obese population with a coefficient value of 0.442 at $1 \%$ and $5 \%$ significance levels. Above all, the correlational analysis reveals in table 1 that there is a moderately significant relationship between the percentage of smokers and percentage of the obese population with a coefficient value of 0.442 at $1 \%$ and $5 \%$ significance levels.

Table 2: Regression Analysis of Depression (Mentally Unhealthy Days), Smoking, and Obesity

\begin{tabular}{|l|l|l|l|}
\hline Variables & Coefficients & T-value & P-values \\
\hline (Constant) & 0.054 & 8.507 & 0.000 \\
\hline$\%$ Smokers & 0.028 & 6.755 & 0.000 \\
\hline$\%$ Obese & 2.121 & 3.779 & 0.000 \\
\hline \multicolumn{4}{|c|}{0.352} \\
\hline R-Square $51.268 * * *$ \\
\hline F-statistics \\
Note: *,**, ***, represents 10\%, 5\%, and 1\% significance level respectively.
\end{tabular}

Table 2 reveals that about $35.2 \%$ variation in depression (or mentally unhealthy days) is explained by the 
percentage of smokers, and the percentage of the obese population in Louisiana.

Also, the global test associated with the F-statistics reveals that the overall depression model is statistically significant at both $1 \%$ and 5\% significance level with an associated F-value of 51.268 and a P-value of 0.000 . In this effect, this model performs better. Table 2 further reveals that there is a significant positive relationship between depression and the percentage of smokers with an associated p-value of 0.000 . Hence, it implies that about $1 \%$ increases in the percentage of smokers will cause about $0.028 \%$ increase in depression. Nonetheless, the data further reveals that there is a significant positive relationship between depression and percentage of the obese population with an associated p-value of 0.000 . This result implies that about $1 \%$ increases in the percentage of the obese people will cause about $2.121 \%$ increase in depression. From the above findings, there is evidence for the researcher to reject the null hypothesis and accept the alternative hypothesis that smoking and obesity are positively related to (or influences) depression.

\subsection{CONCLUSION AND POLICY RECOMMENDATIONS}

This study supported the notion that depressed employees' behaviors have a higher adverse effect on work outcome. Employers' attitudes are vital in effectively managing depression within the workplace. Given the increasing incidence of depression and the need to promote workplace mental health interventions, such approaches may also potentially determine whether implementing these essential programs is successful. The results highlight the need for more considerable attention to an individual with a mental health problem.

- Early symptoms and notification by the management of an employee who is undergoing a level of unhealthy behavior should be advised to seek medical assistance or possibly be enrolled by the administration for support.

- Most often, employees with such challenges feel hated and turn to avoid people. They should be shown more love by their employer, colleagues, and family, given them a sense of belonging, therefore, fulfilling one of Maslow's need of hierarchy.

- A team of adequate follow-up members in the organization should be put in place by management to guide and assist with the challenged employees.

\section{REFERENCES}

Brenninkmeijer, V., Houtman, I., \& Blonk, R. (2008). Depressed and absent from work: Predicting prolonged depressive symptomatology among employees. Occupational Medicine. https://doi.org/10.1093/occmed/kqn043

Center for Health Statistics, N. (2005). NCHS Data Brief, Number 167, October 2014.

Chen, W. Q., Siu, O. L., Lu, J. F., Cooper, C. L., \& Phillips, D. R. (2009). Work stress and depression: The direct and moderating effects of informal social support and coping. Stress and Health. https://doi.org/10.1002/smi.1263

Martin, A. (2010). Individual and contextual correlates of managers' attitudes toward depressed employees. Human Resource Management. https://doi.org/10.1002/hrm.20370

Pratt, L. A., \& Brody, D. J. (n.d.). Key findings Data from the National Health and Nutrition Examination. Retrieved from http://www.cdc.gov/nchs/data/databriefs/db172_table.pdf\#3.

Pratt, L. A., \& Brody, D. J. (2005). Key findings Data from the National Health and Nutrition Examination Surveys. Retrieved from http://www.cdc.gov/nchs/data/databriefs/ 